\section{MORTALITY IN HOSPITALS.}

To the Editor of THe Lancer.

SIR,-Dr. Farr has replied to my criticisms on his method of taking hospital statistics by a very singular letter, and as you nave allowed him in that letter to go into a great variety of matters personal to myself, but quite irrelevant to the subject under discussion, I must request you to afford me the space necessary for a reply.

You will do me the justice, Sir, to allow me to remind your readers that I did not thrust myself into this discussion. I had never seen Dr. Farr's statistics, nor if I had seen them should I have thought of publicly criticiziug them, until in your lead. ing article of Feb. 27th, on the subject, you alluded to the re. searches of Dr. Bristowe and myself, and called on us by im plication to give our experience on the matter. I then procured Dr. Farr's letter to the Registrar-General. I thought his method erroneous, and I said so. I said also that that error would lead to absurd conclusions, as errors generally do. Further, I proved what I said by examples, which Dr. Farr does not attempt to meet. In all this I cannot see how I could be charged with a desire to attack Dr. Farr, or with having passed the bounds of legitimate controversy. My intention was to discuss an abstract question in language strictly moderate; but if I failed in this, and used any terms which can properly be held to be unjustifiable, I am quite willing to retract them. My only object is to understand Dr. Farr, and to form a judg ment upon his data, and his method of using them. The obscurity of his reasoning, and the violence with which he resents criticism, have caused me to form an unfavourable judgment on these points hitherto; but $[$ can assure Dr. Farr that, whatever he may think, I have no prejudices on the matter, and if he can show cause for believing that his method is, as he calls it, "the true method," I will willingly use it; and further, if be can show that it will support his conclusions, I will most willingly subscribe to those conclusions.

Dr. Farr, however, has chosen a different course. Irritated, as it seems, either by my dissent from his opinions, or by some expressions of mine, he replies by a number of charges against me, referring to other matters, and seeks to escape from refutation under a cloud of abuse. He says that the Report which Dr. Bristowe and myself are preparing for the Medical Department of the Privy Council on the subject of Hospitals, was drawn up to support a foregone conclusion, and was intended and used for the purposes of one side, and one side only, in the recent cause about the site of St. Thomas's Hospital. This is not the fact. When Mr. Simon proposed to me to undertake this inquiry he and I were comparative strangers. He had no means of knowing, and did not know, what my views on the subject were. No foregone conclusion was ever hinted at to me, nor would I have undertaken the business on any such terms. To conduct what professes to be an impartial scientific inquiry, but which is really intended to bolster up a private scbeme, is a piece of personal dishonesty which I cannot ima. gine how anybody can charge upon another without proof. Dr. Farr will surely on reflection see cause for feeling ashamed of having advanced a charge so totally calumnious. Dr. Farr, I see, speaks of the affidavits in the recent cause about St. Thomas's Hospital, as if they were supplied from our Report. This, again, is incorrect. I was consulted upon certain points, and gave my opinion in the form of an affidavit. At that time I had not my Report in my possession, nor if I had could I have used it, since it was, of course, the property of the Department for whom it was drawn up. If I had kept a copy of the affidavit, I would enclose it to you. As I have not done so, all I need say is, that I make no objection to its publication, and am ready to support it, word for word, by evidence which I believe will be found satisfactory. But I have no reason to think that the affidavits of Dr. Bristowe and myself had any decisive weight in the cause, which was decided upon a preponderance of evidence furnished by persons who had never seen any line of our Report; nor can these affidavits have any bearing on the trust worthiness of Dr. Farr's statistics. Again, Dr. Farr imports into this discussion, most improperly and irrelevantly, the question of the propriety of my appointment, on the recommendation of Mr. Simon, to report to the Medical Department of the Privy Council on the subject of Hospitals. He also quotes the opinion of an anonymons informant, that the Report will " contain gross blunders, as both Dr. Bristowe and Mr. Holmes are thoroughly inexperienced." In what department our experience is deficient, Dr. Farr has not told us. I will say nothing about this, except that if Mr. Simon has made a bad choice in recom. mending me personally for this duty, he must at any rate be acquitted of any corrupt motive therein, as our acquaintance is one proceeding only from business; and that, as to experience, though I may not have spent years in the manipulation of figures, $I$ have spent the best part of my life for the last fifteen years within the walls of hospitals. Dr. Farr then goes on to insinuate that I am the writer of a review which has displeased him, on Miss Nightingale's " Notes on Hospitals," which is not the fact; I neither wrote that review, nor have the least idea who was the anthor of it.

I pass over the expressions which Dr. Farr thinks it decent to apply to me-such as " incompetent," "prejudiced," "inspired writer," "playing a game," "winning by a trick," \&c. -with the simple remark that this is not the tone in which disputed matters ought to be argued between gentlemen. T'he distinction is a very obvious one between my language of which Dr. Farr complains and that of which he is himself guilty. Mine was applied to his opinions and statements, of which you may say anything moderate, and which can be supported by proof, without passing the limits of fair controversy ; but personal abuse such as he uses to me can only lead to personal quarrels, and should be deprecated.

One word more about this Report. Dr. Farr insinnates that it has been held back until the question of the site of St. Thomas's Hospital was settled. This again is not the fact. Dr. Bristowe and I supplied the MS. to our employers as soon as we could get it ready, and it has been passing through the press ever since in the regular course.

And now, Sir, permit me to break loose from this wretched string of personalities, and to appeal to Dr. Farr's good sense and good feeling not to convert what is a mere scientific question into an angry squabble. If I have expressed myself about Dr. Farr or his method in any terms of which he has just reason to complain, I ask his pardon. I will willingly put up with any thing that he thinks it proper to say about me and about my opinions if he will contrive to explain and defend his own temperately and intelligibly. What is wanted is, that he should sustain, in plain words and by intelligible steps of reasoning, the following propositions, on which his method rests :-1. That the death-rate of hospitals is a satisfactory test of their salu. brity. 2. That the annual death-rate of different hospitals can be fairly compared without taking into consideration the annual number of patients in each. 3. That in the hospitals which he used for the compilation of his tables either $(a)$ the cases treated are of the same class, or $(b)$ the existing differences are taken into account in his system.

Dr. Farr's defence of his method in the letter before me (if it be really intended as such) is, I am sorry to say, unintelligible to me. This does not proceed, as Dr. Farr would wish to represent, from any incompetence on my part to understand arithmetical reasoning, - for I am not altogether unaccustomed to mathematical demonstration, - but from the great obscurity of Dr. Farr's remarks. In one sentence he appears to say that he has arrived at similar results both by his own and by the usual method of statistics, and that they are nearly identical, inasmuch as the mean term of residence is much the same for different hospitals; in another sentence he reproves me for not knowing (what I certainly do not know) that this same mean term of residence is " kept entirely out of account by the common method." If that were so, how could the two methods lead to nearly similar results? But that it is not so I have shown in what Dr. Farr calls my " confused explanation," in which I have pointed out that the total annual population of an hospital (which is the basis of computation in the ordinary method) is the product of two factors-viz., the daily average of beds multiplied by the number of times in the year which each bed changes inmates. And Dr. Farr has refuted his own assertion by translating this statement of mine into algebraical language; for, says he, "it is evident that if $P$ is put for the mean population of an hospital" (or, as I have called it above, the daily average of beds), " $x$ for the mean term of residence in years" (which of course will be a fraction), "and $C$ the number of cases treated annually, we shall have $P=x C$." Let me illustrate this, for those of your readers who are less familiar than Dr. Farr with $P$ and $x$, by an example. Let us suppose our hospital to have 100 beds in daily use, and that the average stay of each inmate is a calendar month, then $P$ will be represented by $100, x$ by $\frac{1}{12}$, or each bed will change inmates on an average twelve times a year; and the number of patients during the year $(C)$ will be 1200 , or, as I put it above, the total annual population is the product of the daily population multiplied by the number of times which each bed changes inmates in the year, and this 
latter number is of course the reciprocal of " the mean term of residence in years." How Dr. Farr, in the face of this his own explanation, can say that the term of residence is kept out of account in the common method I cannot understand, any more than I can understand at what point in his method he brings it in. Why should not Dr. Farr have taken notice of the instance by which I showed the omission of this consideration in the items of his list which referred to the Royal Infirmary and Northern Hospital at Liverpool? But, perhaps, if Dr. Farr would reason calmly with me, I might understand his meaning.

It is hardly candid of Dr. Farr to say that "though we cannot deduce the rate of mortality from the deaths in a single house of any class, we can deduce the mean rate of mortality from several of such houses," when I had expressly barred this argument by pointing out that one of Dr. Farr's classes con. sists of only four, and another of only tive, individuals, so that each amounts to little more than an individual instance; and furtber, that all the five were London hospitals, all the four sitaated in large towns, while those with which they were compared were chiefly if not entirely country hospitals.

Again, the way in which Dr. Farr tries to set aside my hypothetical illustration from the cancer wards and the gene. ral wards of Middlesex Hospital is not very happy. That illustration was a perfectly legitimate application of his own method; nor does Dr. Farr impugu the process by which the result was arrived at, further than to say that "special hospitals" were excluded from his table. But why were they excluded? If the method gives accurate comparisons between hospitals and private houses, why not between general and epecial hospitals? However, my illustration was not drawn from a special hospital, but might be extended to every hospital which has distinct wards for chronic and acute cases, and by parity of reasoning to every pair of chronic and acute hospitals, and to all sums of such pairs. In all such cases Dr. Farr's method would lead to the belief-and a most erroneous one it would generally be-that the hospital which was doing the greatest amount of good was the least salubrious.

Dr. Farr refers to the note appended to his letter to the Registrar.General, in wbich " the reader is informed that the mortality of groups is sufficiently correct, while he is cautioned as to the use of the returns of any one hospital alone." This was precisely one of the features of his method to which I objected. He seems to allow that the separate items, of which his (very short) lists are composed, are inaccurate, and yet to claim accuracy for the sums of them. Can this be a true method? Ought not Dr. Farr to have followed the opposite plan, which is the one usual in arithmetic, and have inferred 姑he trustworthiness of the sum from the proved accuracy of the items?

I feel, Sir, that this letter has already extended to an inor. dinate length : my excuse must be the strange liberty $w$ hich you allowed to Dr. Farr of producing numerous miscellaneous and irrelevant topics. I have many other misunderstandings to complain of ; but there is one which I cannot pass over in silence-I mean the insinuation that I have spoken disrespectfully of Miss Nightingale, and that I wish to undo the good which she has done. I should indeed have reason to be ashamed of myself if I had ever written, spoken, or thought of Miss Nightingale otherwise than with respect. But I submit that her name has been most improperly introdnced by Dr. Farr into this discussion with a view of leading your readers' minds away from what is really in question-viz., will his statistical method bear examination, and will it support the assertions in his letter to the Registrar-General? So much I may perhaps be allowed to say about Miss Nightingale-that the good by which she has earned the love and gratitude of her countrymen and of the whole world was done by personal service and personal work in hospitals, not by summing up figures.

One word in reply to Dr. Farr's P.S. He begs I will not consider him discourteous if he declines further controversy with me. I certainly shall not. His courtesy or discourtesy is not the point in question, nor is it a matter of the least in portance in this discussion. If Dr. Farr, having made use of his public position to bring forward statements of the highest interest on great public question, feels that he is in possession of any facts or arguments to support those statements, he will of course know that it is bis public duty to defend them to the uttermost. But if he can find nothing better to produce than irrelevant and unfounded personalities, he had better with. draw froma a controversy for which he is unfitted. 'The conclusion will be, not that he is discourteous, but that his statements are without foundation.

I am, Sir, yours \&c.,
To the Editor of The LANCeT.

SIR,-I should think that Dr. Farr must already regret the intemperate letter which escaped from him into your journal of last week-a letter which affords a specimen (though $I$ believe an exaggerated specimen) of those very defects of reasoning which such as call in question Dr. Farr's conclusions are wont to attribute to him.

1st. He assumes, on the anthority of his friend Mrs. Harris, that Mr. Holmes and myself are incompetent to perform a certain task which we undertook to perform.

2nd. He assumes, on the authority of the same amiable lady, that " the book," as he chooses to term the report on which we have been engaged, "will contain gross blunders;" and he ventures to criticize some of our assumed blunders of method and of fact.

3rd. He assumes, apparently on bis own authority and by that method of "intuition" which he condemns, that affidavits which were made by Mr. Holmes and myself in reference to the suitability of Stangate as a site for the future St. Thomas's Hospital contained certain arguments, which he takes the trouble to indicate and refute.

In reply, I may be permitted to say-

1st. That Dr. Farr's hasty judgment on the intellectual capabilities of two individuals of whom he evidently knows nothing, beyond the fact that they differ from him in opinion, can be a matter of little importance to those individuals and of none to the public, and would be as useless to discuss as it was indecent to publish.

2nd. That Dr. Farr's conjectural criticism on an imaginary report of ours cannot surely, even by himself, be regarded as a true criticism on our real report, which neither he nor his friend has yet seen, and of the contents of which they are both up to the present moment wholly ignorant.

3rd. That the arguments and opinions which Dr. Farr attributes to our affidavits and believes to have unduly influenced the Vice-Chancellor's recent judgment in the matter of St. Thomas's Hospital, are a pure fiction of Dr. Farr's own. Our affidavits contained no such argument as that which he tries to fasten upon us by combating with so much gusto and selfcomplacency. My affidavit is, I presume, either in the possession of the Court of Chancery or in the hands of the hospital solicitor, Mr. Wainwright, of 6 , Lincoln's.inn ; and, so far as I a m concerned, Dr. Farr is at full liberty to consult it, to pub. lish it, and to criticize it. It contains nothing but what I am fully prepared to defend, and nothing in reference to the Hôtel Dieu beyond what is based on published documents and actual statistics.

The only other points of moment contained in Dr. Farr's letter are, a personal attack on the medical officer of the Privy Council, and a similar attack on my colleague, Mr. Holmes. It would be easy for me to rebut them; but it is obviously no duty of mine to take up the cudgels in behalf of gentlemen so competent as they are to defend themselves.

In conclusion, Sir, let me point out that Dr. Farr evades in this letter, as he has done in former letters, the real question at issue between himself and me. He has spoken of hospitals as "ways of death to their inmates." I have called upon him for the evidence on which he bases this accusation, and he replies by random statements and uncivil language.

I am, Sir, your obedient servant,

Queen-square, Westminster, A pril, 1864.

J. S. BRIstowe, M.D.

\section{ROYAL MEDICAL AND CHIRURGICAL AND PATHOLOGICAL SOCIETIES. To the Editor of THE LANCET.}

SrR, - Mr. Holmes addresses you in the last number of THE LANCET in his character as "Hon. Sec. of the Pathological Society," and desires to remind your readers that what has been said in THE LANCET on the subject of the rent paid by the Pathological Society to the Medico-Chirurgical Society is merely the private opinion of different individuals, and "he is permitted by the President" to inform you that no expression of opinion has been authorized by the Council of the Society. Allow me as a member of the Society to remind Mr. Holmes that $a$ very recent report presented by the Council to the Society alluded in very pointed terms to the amount of rent charged by the Medico-Chirurgical Society; and let me also remind him of more than one communication which has passed between the Councils ou the subject. I take it that the opinion expressed by Mr. Holmes for himself and for our excellen: 